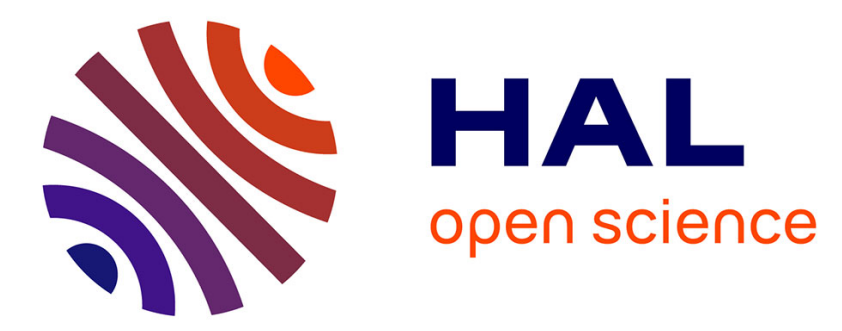

\title{
NCU-G1 is a highly glycosylated integral membrane protein of the lysosome
}

Oliver Schieweck, Markus Damme, Bernd Schröder, Andrej Hasilik, Bernhard Schmidt, Torben Lübke

\section{- To cite this version:}

Oliver Schieweck, Markus Damme, Bernd Schröder, Andrej Hasilik, Bernhard Schmidt, et al.. NCUG1 is a highly glycosylated integral membrane protein of the lysosome. Biochemical Journal, 2009, 422 (1), pp.83-90. 10.1042/BJ20090567 . hal-00479186

\section{HAL Id: hal-00479186 https://hal.science/hal-00479186}

Submitted on 30 Apr 2010

HAL is a multi-disciplinary open access archive for the deposit and dissemination of scientific research documents, whether they are published or not. The documents may come from teaching and research institutions in France or abroad, or from public or private research centers.
L'archive ouverte pluridisciplinaire HAL, est destinée au dépôt et à la diffusion de documents scientifiques de niveau recherche, publiés ou non, émanant des établissements d'enseignement et de recherche français ou étrangers, des laboratoires publics ou privés. 
NCU-G1 is a highly glycosylated

integral membrane protein of the lysosome

Oliver Schieweck ${ }^{1}$, Markus Damme ${ }^{1}$, Bernd Schröder ${ }^{2}$, Andrej Hasilik ${ }^{3}$, Bernhard Schmidt ${ }^{1}$, Torben Lübke ${ }^{1}$

${ }^{1}$ Abteilung Biochemie II, Georg-August-Universität Göttingen, Germany; ${ }^{2}$ Institut für Biochemie, Christian-Albrechts-Universität Kiel, Germany; ${ }^{3}$ Institut für Physiologische Chemie, Philipps-Universität Marburg, Germany

Correspondence: Torben Lübke, Zentrum Biochemie und Molekulare Zellbiologie, Abteilung Biochemie II, Georg-August Universität Göttingen, Heinrich-Düker-Weg 12, D-37073 Göttingen, Germany;

Email: tluebke@gwdg.de Fax:+49-551-395979 Phone : +49-551-395902

Short title: NCU-G1 is a lysosomal membrane protein

\begin{abstract}
Abbreviations used: M6P, mannose 6-phosphate; MPR, mannose 6-phosphate receptor; LAMP, lysosome-associated membrane protein; LIMP, lysosomal integral membrane protein; AP, adaptor protein; GGA, Golgi-localized, gamma-earcontaining, ADP ribosylation factor-binding proteins; TMEM, transmembrane protein; NCL, neuronal ceroid lipofuscinosis; MEF, mouse embryonic fibroblasts; TGN, transGolgi network; MTN, multi-tissue Northern; NPC1, Niemann-Pick Disease type C1; PPAR, peroxisome proliferators-activated receptor; SH3, Src-homology 3; CRBPI, cellular retinol-binding protein type I; GFP, green fluorescent protein; RFP, red fluorescent protein; TNF, tumor necrosis factor
\end{abstract}




\section{Abstract}

Until recently, a modest number of approximately 40 lysosomal membrane proteins had been identified and even fewer were characterized in their function. In a proteomic study, using lysosomal membranes from human placenta we identified several candidate lysosomal membrane proteins and proved the lysosomal localization of two of them. Here, we demonstrate the lysosomal localization of the mouse ortholog of the human $\mathrm{C} 10$ rf85 protein that had been termed kidney predominant protein NCU-G1 (Acc.No: AB027141). NCU-G1 encodes a 404 amino acid protein with a calculated molecular mass of $39 \mathrm{kDa}$. The bioinformatics analysis of its amino acid sequence suggests it is a type I transmembrane protein containing a single tyrosine-based consensus lysosomal sorting motif at position 400 within the 12-residue C-terminal tail. Its lysosomal localization was confirmed using immunofluorescence with a C-terminally His-tagged NCU-G1 and the lysosomal marker LAMP-1 as a reference, and by subcellular fractionation of mouse liver after a tyloxapol-induced density shift of the lysosomal fraction using an anti-NCU-G1 antiserum. In transiently transfected HT1080 and HeLa cells the His-tagged NCU-G1 was detected in two molecular forms with apparent protein sizes of 70 and $80 \mathrm{kDa}$, and in mouse liver the endogenous wild type NCU-G1 was detected as a $75 \mathrm{kDa}$ protein. The remarkable difference between the apparent and the calculated molecular masses of NCU-G1 was shown by digesting the protein with N-glycosidase $\mathrm{F}$ to be due to an extensive glycosylation. The lysosomal localization was impaired by mutational replacement of an alanine for the tyrosine residue within the putative sorting motif. 


\section{Introduction}

Lysosomes are membrane-limited organelles of eukaryotic cells that degrade intracellular and extracellular materials they obtain by autophagy and endocytosis, respectively. Within the lysosomes, more than 60 acid hydrolases and associated cofactors degrade the imported macromolecules [1]. The products of this breakdown are exported into the cytoplasm where they are metabolized. The metabolite export through the lysosomal membrane is less understood than the macromolecular degradation within the lysosomal matrix. Although, the lysosomal v-ATPase, which is required for the acidification of the matrix, is well characterized, the number of transporters is less than expected from that of the solutes which must be released from lysosomes [2, 3]. The importance of these transporters is underscored by the occurrence of lysosomal storage diseases [4]. Thus, a loss of the cystine transporter cystinosin results in cystinosis [5], that of the sialic acid transporter sialin manifests as sialic acid storage diseases [6], of mucolipin as mucolipidosis IV [7-9]. Recently, the lysosomal cobalamin transporter has been identified, which is mutated in cblF defect of vitamin $B_{12}$ metabolism [10]. Inherited defects of the prominent lysosomeassociated membrane protein 2 (LAMP-2) causes Danon disease which is characterized by a (cardio)myopathy due to an abnormal accumulation of phagosomes and autophagosomes [11].

The vast majority of soluble lysosomal proteins are transported from the trans-Golgi network (TGN) to endosomes after receiving a mannose 6-phosphate (M6P) tag at their $\mathrm{N}$-glycans that is recognized by specific mannose 6-phosphate receptors (MPR) [12]. As an exception, the lysosomal soluble hydrolase $\beta$-glucocerebrosidase is directed to the lysosomes by a piggy-back transport along with the lysosomal integral membrane protein type 2 (LIMP-2) [13]. 
Biochemical Journal Immediate Publication. Published on 02 Jun 2009 as manuscript BJ20090567

The lysosomal sorting of most integral lysosomal membrane proteins is mediated by short amino acid sequence motifs in their cytosolic loops and tails. Two types of lysosomal sorting motifs are known On the one hand, the tyrosine-based sorting signals NPXY and $Y X X \Phi$ and, on the other hand, the dileucine-based sorting signals [DE]XXXL[LI] and DXXLL $[14,15]$. These motifs resemble endocytic and trans-Golgi network (TGN) sorting signals, however, they differ from the latter by their close proximity (mostly $6-13$ amino acids) to the transmembrane segment $[16,17]$. They are recognized by the heterotetrameric adaptor proteins AP-1 through -4 or by the multidomain Golgi-localized, gamma-ear-containing, ADP ribosylation factor-binding proteins (GGA) (reviewed by $[14,15])$.

Recently, several novel lysosomal membrane proteins were identified using different strategies such as subcellular fractionation (p40, [18]), genetic approaches (TMEM74 [19], TMEM76 [20], MFSD8 [21]) and proteome studies [22, 23]. Among these, TMEM76 and MFSD8, have been shown to be associated with the lysosomal diseases mucopolysacharidosis $\mathrm{HIC}_{\mathrm{C}}[20,22]$ and a late-infantile onset form of neuronal ceroid lipofuscinosis (NCL) [21]. In a proteomics analysis of lysosomal membranes purified from human placenta we identified 124 lysosomally enriched proteins including 12 novel proteins of unknown function [23]. Two of these, LOC201931 and LOC51622, were shown to localize mainly to the lysosomal compartment using their YFP-tagged versions and immunofluorescence [23]. Here, we verify the lysosomal localization of a third candidate called kidney predominant protein NCU-G1 and show that it represents a highly glycosylated integral membrane protein of the lysosomal compartment. 


\section{Materials and Methods}

Cell lines and cell culture - If not stated otherwise HT1080 cells, HeLa cells and mouse embryonic fibroblasts (MEF) were grown in complete Dulbecco's modified Eagle's medium (DMEM, GIBCO Life Technologies) supplemented with $10 \%$ fetal bovine serum (PAN Biotech $\mathrm{GmbH}$ ), 1\% penicillin/streptomycin (GIBCO Life Technologies) and $1 \%$ L-glutamine (GIBCO Life Technologies) at $37^{\circ} \mathrm{C}$ with $5 \% \mathrm{CO}_{2}$. Antibodies - Antibodies used for this study include monoclonal anti-RGS-His4-tag and anti-His5-Alexa488 conjugated (Qiagen), anti-porin HL31 (Calbiochem), antiglyceraldehyde 3-phosphate dehydrogenase (Gapdh, Santa Cruz), anti-cathepsin D [24], anti-human LAMP-2 (H4B4, Developmental Studies Hybridoma Bank, lowa), anti-mouse LAMP-1 (1D4B; Developmental Studies Hybridoma Bank, lowa) and antiserine carboxypeptidase, Scpep1 [25], antisera. Horse raddish peroxidase, HRP- and fluorescence-conjugated secondary antibodies were supplied by Dianova and Invitrogen, respectively.

Antibody production - A rabbit polyclonal antiserum (anti-NCU-G1) was generated against an internal, putative luminal peptide of mouse NCU-G1 (CPSVNERNSIDDEYAPAVF). The serum was affinity-purified using the immobilized peptide.

Cloning, transfection and expression of NCU-G1-RGS-His5 - The NCU-G1 cDNA (AccNo: BC021547; 1563 bp) was received from the Deutsche Ressourcenzentrum für Genomforschung (RZPD; clone IRAVp968F0636D6) and subcloned into the pcDNA3.1/Hygro(+) vector (Invitrogen) by add-on PCR using the following Nhelforward primer 5'-gtatgctagcATGTTTCGCTGTTGGGGACCTCAC-3' and the NotlRGS-His5-reverse primer 5'gtatgcggccgcTTATCCGTGATGGTGATGGTGCGATCCTCTTCCGTTTATGGACTGG TACTCAGAATACC-3'. Finally, all constructs were full length sequenced to exclude 
unintentional mutations. HT1080 cells, HeLa cells and mouse embryonic fibroblasts (MEF) were transfected with Fugene6 reagent (Roche) as recommended by the manufacturer.

Immunofluorescence - MEF or HeLa cells were transiently transfected and cultivated for $24-36 \mathrm{~h}$. After fixation with methanol, the cells were analysed for immunofluorescence as described before [26] using anti-LAMP-1 (1D4B) and antiLAMP-2 (H4B4) antibodies. His-tagged NCU-G1 protein was detected with an Alexa488-coupled monoclonal anti-pentaHis antibody (Qiagen). The LAMP antibodies were detected with Alexa546-conjugated goat anti-rat or goat anti-mouse IgG secondary antibodies (Invitrogen). Immunofluorescence images were obtained using a Leica TCS Sp2 AOBS laser scan microscope (Leica Microsystems GmbH, Heidelberg, Germany).

Site-directed mutagenesis of NCU-G1 - We inserted the Y400A mutation into the NCU-G1-RGS-His5 construct using the QuikChange site-directed mutagenesis kit (Stratagene) with the 5'-TATTCTGAGGCCCAGTCCATAAAC-3' forward primer and the 5'-GTTTATGGACTGGGCCTCAGAATA-3' reverse primer according to the manufacturer's instruction.

Northern blot - Northern blot analysis was performed as described before [27] with the exception that total mouse RNA from various tissues was separated. NCU-G1 transcripts were detected with the full length NCU-G1 cDNA as a probe. The Northern blot membrane was stripped and re-hybridized with the full length mouse Gapdh cDNA for RNA loading control.

Membrane extraction assay - HeLa cells were transiently transfected with the Histagged NCU-G1 construct and harvested by scraping, extracted in lysis buffer (10 $\mathrm{mM}$ Tris- $\mathrm{HCl}, \mathrm{pH} 7.5$, with a mixture of protease inhibitors) by sonication and finally cleared by centrifugion $\left(10000 \times \mathrm{g}, 10 \mathrm{~min}, 4^{\circ} \mathrm{C}\right)$. The membranes, $200 \mu \mathrm{g}$ protein, 
were subjected to extraction with either $0.1 \mathrm{M}$ sodium carbonate, $\mathrm{pH} 11.5$, or $1 \%$ Triton X100 in lysis buffer, for 30 min on ice. Subsequently, the soluble and the solid fractions were separated by centrifugation at $100.000 \times \mathrm{g}$ and $4{ }^{\circ} \mathrm{C}$ for $90 \mathrm{~min}$. The presence of different antigens in the fractions was examined by Western blotting.

Deglycosylation by PNGase F - Cleared lysates from NCU-G1 transiently transfected HT1080 cells were subjected to PNGase F (Roche) treatment as described previously [28].

Lysosome isolation (tritosomes) - Mice were treated by a single injection of 0.75 mg tyloxapol (Triton WR1339; Sigma)/ g body weight 4 d prior to liver withdrawal. The isolation of tritosomes from tyloxapol-treated and control mice included differential centrifugation and isopycnic centrifugation and resulted in a lysosomeenriched fraction F2 as described before [29, 30]

For the continuous sucrose gradient, the "light mitochondria" fraction (L) fraction as described by de Duve et al. [29] was layered onto a pre-formed $15-30 \%$ continuous sucrose gradient and centrifuged at $190.000 \times g_{\max }$ for 150 min in a Beckman SW 41 Ti rotor. Fractions $(1 \mathrm{ml})$ were collected from the top and analysed by Western blotting. In addition, protein and the activity of $\beta$-hexosaminidase were determined using photometric assays [31].

Bioinformatics analysis - NCU-G1 was analysed bioinformatically using ExPASy (http://au.expasy.org), SignalP prediction server ([32]; http://www.cbs.dtu.dk/services/SignalP-2.0), PSORT II prediction server (http://psort.nibb.ac.jp/form2.html), ELM server (http://elm.eu.org) and TMHMM [33] prediction service (http://www.cbs.dtu.dk/services/TMHMM).

Miscellaneous - Standard techniques were used for Western blotting to PVDF membranes. Antibody-protein complexes were visualized by enhanced chemiluminescence (Pierce). 


\section{Results}

\section{Bioinformatics analysis of mouse NCU-G1}

Human C1orf85 protein, gl 15079485, was identified in a comprehensive proteomics analysis of lysosomal integral and associated membrane proteins from human placenta [23]. Its mouse orthologue NCU-G1 is encoded in chromosome 3 and its cDNA is composed of six exons. The mRNA (AccNo: BC021547) is at least 1563 nucleotides (nt) long and consists of a 26 nt 5'-UTR, a 1215 nt coding sequence and a 3'-UTR. The deduced amino acid sequence of the NCU-G1 protein consists of 404 residues with a molecular mass of approximately $40 \mathrm{kDa}$. The bioinformatics analysis predicts a hydrophobic N-teminal signal peptide (residues $1-35$ ) followed by the main part of the molecule (residues 36 - 369) containing nine putative $\mathrm{N}$ glycosylation sites with the consensus sequence NXS/T, a single transmembrane segment (residues 370 - 392) and a C-terminal tail (residues 393 - 404) as illustrated in Figure $1 \mathrm{~A}$. The C-terminal residue is preceded by a potential tyrosinebased (YXXФ) lysosomal targeting signal with YQSI (aa 400 - 403). These data suggest that NCU-G1 is a type I integral membrane protein with a large luminal Nterminal domain, a single transmembrane segment and a short cytoplasmic tail (Figure 1 B). The protein described here does not show any significant sequence similarity to other proteins except in the C-terminal tail, which resembles those in LAMP-1 and -2 proteins. The tails are short, contain several basic residues next to the transmembrane segment and a single tyrosine-based localization motif at or near their C-terminus.

\section{Cloning and expression of NCU-G1}

The NCU-G1 cDNA was received in the pCMV-SPORT6 vector from the Deutsche Ressourcenzentrum für Genomforschung $\mathrm{GmbH}$ (RZPD) and expressed as a C- 
terminal RGS-His-tagged derivative after subcloning by add-on PCR into the pcDNA3.1/Hygro(+) vector (see Material and Methods section). Expression of the Cterminal His-tagged NCU-G1 in various cell types like HT1080 cells (HT1080-NCUG1) or HeLa cells and analysis of the cell lysates by Western blotting using an antiHis-antibody resulted in two bands with apparent molecular weights of about 70 and $80 \mathrm{kDa}$, respectively (Figure $2 \mathrm{~A}$, left panel). For further characterization of the endogenous NCU-G1 protein, we raised a polyclonal antiserum in rabbit against the peptide CPSVNERNSIDDEYAPAVF (residues 245 - 263) that detected two polypeptides at molecular weights comparable to the anti-His-tag antibody (Figure 2 A, right panel).

\section{N-glycosylation of NCU-G1}

Incubations of HT1080 (Figure 2 B, lane 1 \& 2) and HT1080-NCU-G1 cell lysates (Figure 2 B, lane $3 \& 4$ ) with glycosidase PNGase F and analysis by Western blotting resulted in a major decrease in the apparent molecular by approximately $40 \%$ (Figure $2 \mathrm{~B}$ ). In the treated sample two band were observed at 37 and $44 \mathrm{kDa}$ (Figure $2 \mathrm{~B}$, lane 4) as compared to the expected value of $43.8 \mathrm{kDa}$. This result suggests that the existence of two glycosylated molecular forms of NCU-G1 in HT1080 cells is due to differences in the polypeptide rather than in the carbohydrate moieties. Deglycosylation of endogenous NCU-G1 in a lysosome-enriched fraction (F2) that was derived from a tyloxapol-treated mouse liver resulted a similar shift from a 75 kDa glycosylated form of NCU-G1 (Figure $2 \mathrm{~B}$, lane 5) to 40 kDa (Figure 2 B, lane 6).

\section{NCU-G1 is an integral membrane protein}

In order to demonstrate that mouse NCU-G1 is an integral membrane protein, we performed an extraction assay. Homogenates from NCU-G1 transfected and 
untransfected HeLa cells (50 $\mathrm{mg}$ protein) were incubated for $30 \mathrm{~min}$ on ice with homogenisation buffer as a control, $0.1 \mathrm{M}$ sodium carbonate $(\mathrm{pH} 11.5)$ or $1 \%$ Triton $\mathrm{X}-100$. After the incubation, supernatant and pellet fractions were separated by ultracentrifugation at $100.000 \times \mathrm{g}$ and analysed by immunoblotting for NCU-G1-His with the anti-His antibody and the mitochondrial integral membrane protein porin 31HL using a porin-specific monoclonal antibody (Figure $2 \mathrm{C}$ ). In the Western blot analysis, NCU-G1-His was almost completely recovered in the pellet fraction after incubation in the homogenisation buffer. However, NCU-G1-His was partially solubilized in the presence of sodium carbonate and largely solubilized in the presence of Triton $\mathrm{X}-100$ thus resembling the integral membrane protein porin $31 \mathrm{HL}$ (Figure $2 \mathrm{C}$ ).

\section{Tissue distribution of NCU-G1}

The transcription pattern of NCU-G1 was analysed by using a mouse multi-tissue Northern blot (MTN) containing $10 \mu \mathrm{g}$ of total RNA derived from various tissues. The MTN was hybridized with the 1215 bp full-length cDNA probe that identified a single NCU-G1 transcript of $1.5 \mathrm{~kb}$ widely expressed in most mouse tissues (Figure $3 \mathrm{~A}$ ). As expected, NCU-G1 (also termed kidney predominant protein) expression was highest in kidney. The signal was significantly less in samples from liver, brain, intestine, testis, spleen, heart and lung. Interestingly, no NCU-G1 transcript could be detected in skeletal muscle.

The Western blot analyses of various tissues with the NCU-G1 antiserum that was raised against the peptide from amino acid 245 to 263 were hampered by a number of probably non-specific signals (data not shown). As shown before, NCU-G1 was detectable in a lysosomally- enriched fraction from mouse liver with an apparent size of $75 \mathrm{kDa}$ (Figure $2 \mathrm{~B}$, lane 5). 


\section{Subcellular localization of NCU-G1-His by immunofluorescence}

The anti-NCU-G1 antiserum was not suitable for immunofluorescence since many structures in addition to lysosomes were stained. Therefore, we confirmed the Iysosomal localization of NCU-G1 by immunofluorescence with the C-terminal Histagged NCU-G1 derivative in mouse embryonic fibroblasts (MEF) and HeLa cells (not shown). For visualizing we used a monoclonal anti-penta-His antibody that was directly coupled with the chromophore Alexa488. NCU-G1 presented in punctuated vesicular structures throughout the cell. These were shown to represent lysosomes and late endosomes by co-staining with the lysosomal membrane protein LAMP-1 (Figure $4 \mathrm{~A}$ ).

Assuming NCU-G1 is a type I integral membrane protein, its topology suggests a single putative tyrosine-based lysosomal sorting motif YQSI in close proximity of the C-terminus and the transmembrane segment. In order to analyse the role of this putative motif we replaced the tyrosyl residue in position 400 by an alanyl residue by site-directed mutagenesis of the His-tagged NCU-G1 construct (NCU-G1-Y400A). The corresponding expression vector was introduced into HeLa cells and the subcellular localization of NCU-G1-Y400A was analysed by immunofluorescence using the Alexa488-coupled anti-His antibody and compared to that of the lysosomal marker LAMP-2. An extensive co-localization was observed with the NCU-G1 wild type construct. However, the NCU-G1-Y400A mutant was found in a diffuse peripheral network resembling the ER (Figure $4 \mathrm{~B}$ ) and rarely in the LAMP-2-positive organelles.

\section{Subcellular localization of endogenous NCU-G1 using density centrifugation}


Tyloxapol (Triton WR1339) is a nonionic detergent that upon intravenous injection inhibits the lipoprotein lipase and thus increases serum lipoprotein levels like VLDL. Endocytosis of these lipoproteins and the detergent into hepatocytes causes a decrease in the buoyant density of the lysosomes. Upon fractionation in a density gradient the lysosomes of this cell population are shifted towards the top fraction and the resulting lysosome-enriched fraction (F2) is virtually devoid of other organelles mitochondria in particular. We prepared a "light mitochondria fraction" $(L)$ from either tyloxapol-treated or non-treated mouse liver and applied it to a discontinuous sucrose gradient. After the separation we analysed the resulting fractions F1 - F4 (50 $\mu \mathrm{g}$ protein each) by immunoblotting (Figure $4 \mathrm{C}$ ). In the control liver, in fractions of the sucrose gradient very small amounts of endogenous NCU-G1 and LAMP-1 were detected (Figure $4 \mathrm{C}$, left panel). Both proteins were detected in fraction F4 which corresponds to the load of the gradient with the $L$ fraction, although, their signals are weaker because mitochondrial proteins represent a major part of fraction F4 and hence dilute the lysosomal proteins. . In contrast, in the tyloxapol-treated liver, NCUG1 (75 kDa) as well as LAMP-1 shifted into fraction F2 due to the selectively altered density of the lysosomes (Figure $4 \mathrm{C}$, right panel). The tyloxapol-induced shift of both NCU-G1 and LAMP-1 is considered a specific proof for the lysosomal localization of the former.

Furthermore, we loaded the $L$ fraction from tyloxapol-treated and control mice onto a preformed continuous sucrose gradient ranging from $15-30 \%$ and observed a similar tyloxapol-induced shift specific to lysosomes. In the control mouse, NCU-G1, LAMP-1 and the soluble lysosomal protein Scpep1 [25] were collected in the pellet of the sucrose gradient (Figure $5 \mathrm{~A}$ ). After tyloxapol treatment all three proteins as well as the lysosomal marker $\beta$-hexosaminidase entered the gradient (Figure $5 \mathrm{~B}, \mathrm{C}$ ). In the control $6 \%$ of the total activity of the marker was found in fractions $7-10$, 
whereas, in tyloxapol treated samples this proportion was increased to $47 \%$ of total. These results in combination with the immunofluorescence data suggest clearly that NCU-G1 is a lysosomal or endosomal protein.

\section{Discussion}

In a recent proteome analysis of the lysosomal membrane from human placenta, we identified 58 known lysosomal membrane proteins including 17 polypeptides of the vATPase and most interestingly twelve novel proteins of so far unknown function that were highly enriched in the lysosomal membrane fraction [23]. For two of these twelve candidates (LOC201931 and LOC51622), we were able to confirm their lysosomal localization with the help of YFP-tagged variants of the proteins [23]. Here, we validate the lysosomal localization and provide first insights into the molecular features of the third candidate derived from that particular subproteome analysis called NCU-G1 (C1orf85) in mouse. Using a proteomics approach, the human NCUG1 orthologue (RGSV2553) was identified as a candidate lysosomal membrane protein. Although, the sequence coverage has reached merely $20 \%$ of the 406 amino acid residues of the human precursor form, all the recovered peptides were detected in similar enrichments as the LAMP-1 and -2 proteins [23]. An inspection of the sequence indicated that most of the remaining peptides of NCU-G1 were not suited for detection either because of size limits or due to glycosylation.

\section{NCU-G1 is a lysosomal protein}

Using immunofluorescence and two different density centrifugation techniques, we show that mouse NCU-G1 co-localizes and/or co-fractionates with the lysosomal marker proteins LAMP-1, Scpep1 and $\beta$-hexosaminidase. This conclusion is 
supported by the finding that NCU-G1 is subject to the tyloxapol (Triton WR1339)induced density shift with a selective decrease in the buoyant density of lysosomes, which has been described by others $[30,34]$. Recently, other putative lysosomal proteins were confirmed to be of lysosomal origin by comparable density-shift techniques $[18,35]$. Our results in conjunction with the enrichment of human NCU-G1 in a lysosomal membrane fraction derived from human placenta [23] strongly support the lysosomal localization of NCU-G1.

Our observation that a mutant of the single putative lysosomal sorting motif (Y400QSI) of NCU-G1 only marginally co-localized with the lysosomal marker LAMP1 indicates that this signal is sufficient to mediate transport towards the lysosomal compartment. Typically, the canonical tyrosine-based sorting signals $Y X X \Phi)$ are $\mathrm{N}-$ terminally flanked by amino acids with a small side chain, mostly a glycine residue as known in e.g. the LAMP proteins $(-1 ;-2 A-C ;-3)$, cystinosin or the acid phosphatase precursor [15]. However, the mucin-like type I membrane protein endolyn exhibits a tyrosine-based sorting signal that is preceded by an asparagine residue instead of

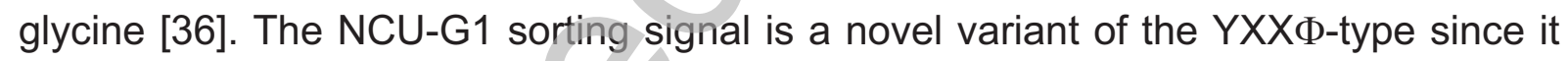
has a glutamic acid residue in position -1. It should be of interest whether the 12 amino acid NCU-G1 cytoplasmic tail could mediate lysosomal transport of other type I transmembrane proteins such as has been shown for the 10 amino acid tail of endolyn [36].

NCU-G1 is widely expressed and highly glycosylated integral membrane protein

The bioinformatics analysis of mouse NCU-G1 predicted a $40 \mathrm{kDa}$ type I transmembrane protein with a 35 residues $\mathrm{N}$-terminal signal peptide, a large luminal domain with nine putative $\mathrm{N}$-glycosylation sites and a single C-terminal 
Biochemical Journal Immediate Publication. Published on 02 Jun 2009 as manuscript BJ20090567

transmembrane segment encompassing residues 370 to 392 and preceding a short cytosolic tail. Initially, the NCU-G1 cDNA was identified in a PCR-based approach to clone a potential prototype of the complement protein $\mathrm{C} 3$ from the mouse embryonic carcinoma cell line F9 [37]. Although NCU-G1 cDNA was the only PCR product, it showed little homology to mouse C3. Northern blot analyses with a NCU-G1-specific probe revealed a single 1.5-kb transcript [37]. The highest expression levels were detected in kidney so that NCU-G1 was also termed synonymously kidney predominant protein 1 [37]. Our Northern blot analysis resembles those observations regarding the ubiquitous expression of NCU-G1 with the exception that no transcript was detected in skeletal muscles. On protein level, our NCU-G1 antiserum hardly detected NCU-G1 even in mouse kidney homogenates in which high amounts of NCU-G1 transcripts were shown. However, endogenous NCU-G1 was detectable in a lysosome-enriched fraction from mouse liver, although, at an unexpected molecular range of about $75 \mathrm{kDa}$. The expression of NCU-G1 in different cell lines came up with comparable apparent molecular sizes of about 70 - $80 \mathrm{kDa}$. Our deglycosylation assays using PNGase F clearly demonstrate that the remarkable difference between calculated and apparent size of NCU-G1 was due to an extensive glycosylation suggesting that most of its nine $\mathrm{N}$-glycosylation sites are used. This observation is not astonishing since many lysosomal membrane proteins including the type I LAMP and the LIMP proteins [38] as well as multipass transmembrane proteins NPC1 [39], cystinosin [40] and others show significantly higher apparent molecular weights than calculated from their primary sequence. The function of the extensive glycosylation of many lysosomal proteins and of lysosomal membrane proteins is assigned to a protective function in two respects: It had been estimated that particularly the high amount of LAMP proteins in the lysosomal membrane generate a glycocalyx that 
Biochemical Journal Immediate Publication. Published on 02 Jun 2009 as manuscript BJ20090567

lines the limiting membrane [41]. In addition, N-glycans are known to protect lysosomal membrane proteins such as LAMP-1 and -2 from proteolysis [42].

We also demonstrated by a membrane extraction assay that C-terminally His-tagged NCU-G1 from HeLa cells is most likely an integral membrane protein although a significant amount of NCU-G1 was already solubilized from the lysosomal membrane upon carbonate treatment. It is worth mentioning that NCU-G1 in a lysosomeenriched fraction F2 from mouse liver showed similar extraction behaviour and was also partially solubilized by sodium carbonate (data not shown).

The present results are contrasting a recently published characterization in which human NCU-G1 was reported to function as a transcription factor and as a nuclear receptor activator for the peroxisome proliferators-activated receptors (PPAR)-alpha [43]. The authors of that study expressed the human NCU-G1 in Drosophila Schneider S2-cells and detected a protein with an apparent molecular size of around $45 \mathrm{kDa}$ in size using a polyclonal antiserum against a peptide representing the last fifteen amino acids. The authors did not identify the N-terminal signal sequence nor a putative transmembrane segment but allocated two nuclear export signals and several potential Src-homology $3(\mathrm{SH} 3)$ interacting domains to the NCU-G1 protein. The authors also showed by chloramphenicol acetyl-transferase assays that NCU-G1 might bind to and activate transcription from a cellular retinol-binding protein type I (CRBPI)-promotor [43]. However, immunofluorescence studies with a C-terminal GFP-tagged version of NCU-G1 and a RFP-tagged version of PPAR showed negligible co-localization of these proteins. While the nuclear protein PPAR was exclusively sorted to the nucleus, NCU-G1 largely localized to extranuclear compartments and this was attributed to a possible interference by the GFP-moiety [43]. 
Here, we demonstrate that NCU-G1 is a highly-glycosylated, integral membrane protein of the lysosomal compartment. Although, the function of NCU-G1 is unknown and the protein does not exhibit homology to known proteins, it may be predicted that NCU-G1 fulfils a function similar to other type I lysosomal membrane proteins such as LAMP-1 and -2. Furthermore, NCU-G1 could be involved in the transport of lysosomal hydrolases as described for the LIMP-2 that binds and directs the soluble hydrolase $\beta$-glucocerebrosidase towards the lysosome in a mannose 6-phosphateindependent manner [13] or in forming larger complexes such as described for nicastrin in the $\gamma$-secretase complex [44]. Unfortunately, our attempts to establish a stably NCU-G1 expressing cell line were not successful, although, we tested the Histagged NCU-G1 in several cell lines such as HeLa, HT1080 and HEK cells (data not shown). Initially, a few cells survived the hygromycin selection protocol, however, the subsequent loss of the cells suggested that a NCU-G1 gain-of-function somehow interfered with cell survival. It is well described that the release of lysosomal proteases e.g. cathepsins is one prerequisite for apoptosis $[45,46]$ and recently it was demonstrated that the lysosomal protease CLN2 plays a critical role in TNFinduced Bid-cleavage [47]

The physiological role of NCU-G1 remains to be characterized. Towards this goal we are generating a NCU-G1-deficient mouse model and examine the expression of the luminal domain of NCU-G1 and search for interacting proteins using immunoprecipitation and affinity chromatography.

\section{Acknowledgements}

We thank Ellen Eckermann-Felkl, Nicole Eiselt and Klaus Neifer for excellent technical assistance as well as Karthikeyan Radhakrishnan and Sebastian Krol for their help and discussions. 


\section{Funding}

This work was supported by the Deutsche Forschungsgemeinschaft grant LU1173/14 (T.L.) and the BMBF grant 031U204A.

\section{References}

1 Lubke, T., Lobel, P. and Sleat, D. E. (2009) Proteomics of the lysosome. Biochim Biophys Acta. 1793, 625-635

2 Saftig, P. (2005) Lysosomes. Landes Bioscience/Eurekah.com

Springer Science+Business Media,

New York

3 Sagne, C. and Gasnier, B. (2008) Molecular physiology and pathophysiology of lysosomal membrane transporters. Journal of inherited metabolic disease

4 Ruivo, R., Anne, C., Sagne, C. and Gasnier, B. (2008) Molecular and cellular basis of lysosomal transmembrane protein dysfunction. Biochim Biophys Acta

5 Town, M., Jean, G., Cherqui, S., Attard, M., Forestier, L., Whitmore, S. A., Callen, D. F., Gribouval, O., Broyer, M., Bates, G. P., van't Hoff, W. and Antignac, C. (1998) A novel gene encoding an integral membrane protein is mutated in nephropathic cystinosis. Nature genetics. 18, 319-324

6 Verheijen, F. W., Verbeek, E., Aula, N., Beerens, C. E., Havelaar, A. C., Joosse, M., Peltonen, L., Aula, P., Galjaard, H., van der Spek, P. J. and Mancini, G. M. (1999) A new gene, encoding an anion transporter, is mutated in sialic acid storage diseases. Nature genetics. 23, 462-465

7 Bargal, R., Avidan, N., Ben-Asher, E., Olender, Z., Zeigler, M., Frumkin, A., RaasRothschild, A., Glusman, G., Lancet, D. and Bach, G. (2000) Identification of the gene causing mucolipidosis type IV. Nature genetics. 26, 118-123

8 Sun, M., Goldin, E., Stahl, S., Falardeau, J. L., Kennedy, J. C., Acierno, J. S., Jr., Bove, C., Kaneski, C. R., Nagle, J., Bromley, M. C., Colman, M., Schiffmann, R. and Slaugenhaupt, S. A. (2000) Mucolipidosis type IV is caused by mutations in a gene encoding a novel transient receptor potential channel. Human molecular genetics. 9, 2471-2478

9 Bassi, M. T., Manzoni, M., Monti, E., Pizzo, M. T., Ballabio, A. and Borsani, G. (2000) Cloning of the gene encoding a novel integral membrane protein, mucolipidin-and identification of the two major founder mutations causing mucolipidosis type IV. Am J Hum Genet. 67, 1110-1120

10 Rutsch, F., Gailus, S., Miousse, I. R., Suormala, T., Sagne, C., Toliat, M. R., Nurnberg, G., Wittkampf, T., Buers, I., Sharifi, A., Stucki, M., Becker, C., Baumgartner, M., Robenek, H., Marquardt, T., Hohne, W., Gasnier, B., Rosenblatt, D. S., Fowler, B. and Nurnberg, P. (2009) Identification of a putative lysosomal cobalamin exporter altered in the cblF defect of vitamin B12 metabolism. Nature genetics. 41, 234-239

11 Tanaka, Y., Guhde, G., Suter, A., Eskelinen, E. L., Hartmann, D., Lullmann-Rauch, R., Janssen, P. M., Blanz, J., von Figura, K. and Saftig, P. (2000) Accumulation of autophagic vacuoles and cardiomyopathy in LAMP-2-deficient mice. Nature. 406, 902-906 
12 Kornfeld, S. and Mellman, I. (1989) The biogenesis of lysosomes. Annual review of cell biology. 5, 483-525

13 Reczek, D., Schwake, M., Schroder, J., Hughes, H., Blanz, J., Jin, X., Brondyk, W., Van Patten, S., Edmunds, T. and Saftig, P. (2007) LIMP-2 is a receptor for lysosomal mannose-6-phosphate-independent targeting of beta-glucocerebrosidase. Cell. 131, 770-783

14 Bonifacino, J. S. and Traub, L. M. (2003) Signals for sorting of transmembrane proteins to endosomes and lysosomes. Annual review of biochemistry. 72, 395-447

15 Braulke, T. and Bonifacino, J. S. (2009) Sorting of lysosomal proteins. Biochim Biophys Acta. 1793, 605-614

16 Geisler, C., Dietrich, J., Nielsen, B. L., Kastrup, J., Lauritsen, J. P., Odum, N. and Christensen, M. D. (1998) Leucine-based receptor sorting motifs are dependent on the spacing relative to the plasma membrane. J Biol Chem. 273, 21316-21323

17 Rohrer, J., Schweizer, A., Russell, D. and Kornfeld, S. (1996) The targeting of Lamp1 to lysosomes is dependent on the spacing of its cytoplasmic tail tyrosine sorting motif relative to the membrane. The Journal of cell biology. 132, 565-576

18 Boonen, M., Hamer, I., Boussac, M., Delsaute, A. F., Flamion, B., Garin, J. and Jadot, M. (2006) Intracellular localization of p40, a protein identified in a preparation of lysosomal membranes. The Biochemical journal. 395, 39-47

19 Yu, C., Wang, L., Lv, B., Lu, Y., Zeng, L., Chen, Y., Ma, D. and Shi, T. (2008) TMEM74, a lysosome and autophagosome protein, regulates autophagy. Biochemical and biophysical research communications. 369, 622-629

20 Hrebicek, M., Mrazova, L., Seyrantepe, V., Durand, S., Roslin, N. M., Noskova, L., Hartmannova, H., Ivanek, R., Cizkova, A., Poupetova, H., Sikora, J., Urinovska, J., Stranecky, V., Zeman, J., Lepage, P., Roquis, D., Verner, A., Ausseil, J., Beesley, C. E., Maire, I., Poorthuis, B. J., van de Kamp, J., van Diggelen, O. P., Wevers, R. A., Hudson, T. J., Fujiwara, T. M., Majewski, J., Morgan, K., Kmoch, S. and Pshezhetsky, A. V. (2006) Mutations in TMEM76* cause mucopolysaccharidosis IIIC (Sanfilippo C syndrome). Am J Hum Genet. 79, 807-819

21 Siintola, E., Topcu, M., Aula, N., Lohi, H., Minassian, B. A., Paterson, A. D., Liu, X. Q., Wilson, C., Lahtinen, U., Anttonen, A. K. and Lehesjoki, A. E. (2007) The novel neuronal ceroid lipofuscinosis gene MFSD8 encodes a putative lysosomal transporter. Am J Hum Genet. 81, 136-146

22 Fan, X., Zhang, H., Zhang, S., Bagshaw, R. D., Tropak, M. B., Callahan, J. W. and Mahuran, D. J. (2006) Identification of the gene encoding the enzyme deficient in mucopolysaccharidosis IIIC (Sanfilippo disease type C). Am J Hum Genet. 79, 738-744

23 Schroder, B., Wrocklage, C., Pan, C., Jager, R., Kosters, B., Schafer, H., Elsasser, H. P., Mann, M. and Hasilik, A. (2007) Integral and associated lysosomal membrane proteins. Traffic. 8, 1676-1686

24 Pohlmann, R., Boeker, M. W. and von Figura, K. (1995) The two mannose 6phosphate receptors transport distinct complements of lysosomal proteins. J Biol Chem. 270, 27311-27318

25 Kollmann, K., Damme, M., Deuschl, F., Kahle, J., D'Hooge, R., Lullmann-Rauch, R. and Lubke, T. (2009) Molecular characterization and gene disruption of mouse lysosomal putative serine carboxypeptidase 1. FEBS J. 276, 1356-1369

26 Kollmann, K., Mutenda, K. E., Balleininger, M., Eckermann, E., von Figura, K., Schmidt, B, and Lubke, T. (2005) Identification of novel lysosomal matrix proteins by proteome analysis. Proteomics. 5, 3966-3978

27 Lubke, T., Marquardt, T., Etzioni, A., Hartmann, E., von Figura, K. and Korner, C. (2001) Complementation cloning identifies CDG-IIc, a new type of congenital disorders of glycosylation, as a GDP-fucose transporter deficiency. Nature genetics. 28, 73-76 
28 Deuschl, F., Kollmann, K., von Figura, K. and Lubke, T. (2006) Molecular characterization of the hypothetical $66.3-\mathrm{kDa}$ protein in mouse: lysosomal targeting, glycosylation, processing and tissue distribution. FEBS letters. 580, 5747-5752

29 de Duve, C., Pressman, B., Gianetto, R., Wattiaux, R. and Appelmans, F. (1955) Tissue fraction studies. 6. Intracellular distribution patterns of enzymes in rat liver tissue. The Biochemical journal, 604-617

30 Wattiaux, R., Wibo, M. and Baudhuin, P. (1963) [Effect of the injection of Triton WR 1339 on the hepatic lysosomes of the rat.]. Archives internationales de physiologie et de biochimie. 71, 140-142

31 Koster, A., Saftig, P., Matzner, U., von Figura, K., Peters, C. and Pohlimann, R. (1993) Targeted disruption of the M(r) 46,000 mannose 6-phosphate receptor gene in mice results in misrouting of lysosomal proteins. EMBO J. 12, 5219-5223

32 Bendtsen, J. D., Nielsen, H., von Heijne, G. and Brunak, S. (2004) Improved prediction of signal peptides: SignalP 3.0. Journal of molecular biology. 340, 783-795

33 Krogh, A., Larsson, B., von Heijne, G. and Sonnhammer, E. L. (2001) Predicting transmembrane protein topology with a hidden Markov model: application to complete genomes. Journal of molecular biology. 305, 567-580

34 Wattiaux, R., Jadot, M., Dubois, F. and Wattiaux-De Coninck, S. (1996) Phagocytosis by rat liver: relationships between phagosomes and lysosomes. Biochemical and biophysical research communications. 220, 569-574

35 Della Valle, M. C., Sleat, D. E., Sohar, I., Wen, T., Pintar, J. E., Jadot, M. and Lobel, P. (2006) Demonstration of lysosomal localization for the mammalian ependymin-related protein using classical approaches combined with a novel density shift method. J Biol Chem. 281, 35436-35445

36 Ihrke, G., Gray, S. R. and Luzio, J. P. (2000) Endolyn is a mucin-like type I membrane protein targeted to lysosomes by its cytoplasmic tail. The Biochemical journal. 345 Pt 2, 287296

37 Kawamura, T., Kuroda, N., Kimura, Y., Lazoura, E., Okada, N. and Okada, H. (2001) cDNA of a novel mRNA expressed predominantly in mouse kidney. Biochem Genet. 39, 3342

38 Hunziker, W. and Geuze, H. J. (1996) Intracellular trafficking of lysosomal membrane proteins. Bioessays. 18, 379-389

39 Watari, H., Blanchette-Mackie, E. J., Dwyer, N. K., Watari, M., Neufeld, E. B., Patel, S., Pentchev, P. G. and Strauss, J. F., 3rd. (1999) Mutations in the leucine zipper motif and sterol-sensing domain inactivate the Niemann-Pick C1 glycoprotein. J Biol Chem. 274, 21861-21866

40 Cherqui, S., Kalatzis, V., Trugnan, G. and Antignac, C. (2001) The targeting of cystinosin to the lysosomal membrane requires a tyrosine-based signal and a novel sorting motif. J Biol Chem. 276, 13314-13321

41 Neiss, W. F. (1984) A coat of glycoconjugates on the inner surface of the lysosomal membrane in the rat kidney. Histochemistry. 80, 603-608

42 Kundra, R. and Kornfeld, S. (1999) Asparagine-linked oligosaccharides protect Lamp1 and Lamp-2 from intracellular proteolysis. J Biol Chem. 274, 31039-31046

43 Steffensen, K. R., Bouzga, M., Skjeldal, F., Kasi, C., Karahasan, A., Matre, V., Bakke, O., Guerin, S. and Eskild, W. (2007) Human NCU-G1 can function as a transcription factor and as a nuclear receptor co-activator. BMC Mol Biol. 8, 106

44 Li, T., Ma, G., Cai, H., Price, D. L. and Wong, P. C. (2003) Nicastrin is required for assembly of presenilin/gamma-secretase complexes to mediate Notch signaling and for processing and trafficking of beta-amyloid precursor protein in mammals. J Neurosci. 23, $3272-3277$ 
45 Kroemer, G. and Jaattela, M. (2005) Lysosomes and autophagy in cell death control. Nat Rev Cancer. 5, 886-897

46 Chwieralski, C. E., Welte, T. and Buhling, F. (2006) Cathepsin-regulated apoptosis. Apoptosis. 11, 143-149

47 Autefage, H., Albinet, V., Garcia, V., Berges, H., Nicolau, M. L., Therville, N., Altie, M. F., Caillaud, C., Levade, T. and Andrieu-Abadie, N. (2009) The lysosomal serine protease CLN2 regulates TNF alpha-mediated apoptosis in a bid-dependent manner. J Biol Chem

\section{Tables and Figures}

Figure 1 Predicted structure of NCU-G1

(A) The NCU-G1 cDNA encodes a protein of 404 amino acids that contains a predicted signal peptide (underlined), nine putative $\mathrm{N}$-glycosylation sites (NXS/T, in bold), a single transmembrane segment (framed) and a putative tyrosine-based sorting signal (YQSI; bold and underlined).

(B) Schematic drawing of the predicted topology of NCU-G1 after cleaving of the signal peptide (residues $1-35$ ). The putative $\mathrm{N}$-glycosylation sites, the predicted 
transmembrane segment and the potential tyrosine-based sorting signal are indicated.

\section{Figure 2 Molecular characterization of NCU-G1}

(A) Aliquots, $50 \mu \mathrm{g}$ protein, of cell extracts from non-transfected HT1080 cells (-) and HT1080 cells that were transiently transfected with a C-terminal His-tagged NCU-G1 variant $(+)$ were separated by SDS-PAGE and analysed by Western blot analysis using either an anti-His antibody (left panel) or a anti-NCU-G1 antiserum (right panel).

(B) Aliquots, $100 \mu \mathrm{g}$ protein, of cell extracts from non-transfected HT1080 cells (lanes 1 and 2) and HT1080 cells that were transiently transfected with a C-terminal Histagged NCU-G1 variant (lanes 3 and 4) were incubated in the absence (-) or presence $(+)$ of PNGase $\mathrm{F}(1 \mathrm{U})$ over night at $37^{\circ} \mathrm{C}$ and subsequently analysed by immunoblotting using the anti-NCU-G1 antiserum. $50 \mu \mathrm{g}$ of a lysosome-enriched fraction (F2, lanes 5 and 6) were treated with $1 U$ of PNGase under the same conditions and analysed as described above. The glycosylated forms of NCU-G1 are indicated by closed $(\Rightarrow$ ) and the deglycosylated NCU-G1 forms by open arrows $(\Rightarrow)$. (C) Control (-) and NCU-G1-transfected Hela cell extracts were prepared as described in the Material and methods section and subsequently subjected to a membrane extraction assay using either lysis buffer, $0.1 \mathrm{M}$ sodium carbonate or Triton-X100 for $30 \mathrm{~min}$ on ice. After a $100000 \times \mathrm{g}$ centrifugation for $60 \mathrm{~min}$, the obtained supernatants $(\mathrm{SN})$ and pellets $(\mathrm{P})$ were analysed by Western blotting using an anti-His antibody. After stripping with $0.2 \mathrm{~N} \mathrm{NaOH}$ for $5 \mathrm{~min}$ and re-equilibration, the membrane was analysed with an anti-porin $31 \mathrm{HL}$ monoclonal antibody.

\section{Figure 3 Expression pattern of NCU-G1}


Biochemical Journal Immediate Publication. Published on 02 Jun 2009 as manuscript BJ20090567

\section{3}

Northern blot analysis of NCU-G1 in various mouse tissues. Aliquots of total RNA from various tissues, $10 \mu \mathrm{g}$, were separated and sequently hybridized with a full length cDNA NCU-G1 probe and a full length Gapdh probe, respectively.

\section{Figure 4 Subcellular localization of NCU-G1 and NCU-G1-Y400A}

(A) Co-immunolocalization of NCU-G1 and the lysosomal membrane protein LAMP1. Mouse embryonic fibroblasts were transiently transfected with the C-terminally Histagged NCU-G1 construct and fixed with ice-cold methanol. NCU-G1-His5 was detected by direct immunofluorescence and LAMP-1 was detected using the established anti-LAMP-1 antibody (1D4B) originating from rat by indirect immunofluorescence.

(B) Immunostaining of NCU-G1-Y400A in HeLa cells. The C-terminally His-tagged NCU-G1-Y400A construct was mutated in the C-terminal putative tyrosine-based lysosomal sorting motif. HeLa cells were transiently transfected with the NCU-G1Y400A construct and fixed with methanol after 24 h. His-tagged NCU-G1-Y400A was detected as described above. The cellular distribution of the human LAMP-2 was analysed by indirect immunofluorescence using the anti-LAMP-2 antibody (H4B4).

(C) Schematic centrifugation procedure to obtain a lysosome-enriched fraction F2 which is finally harvested from the interphase between $1.06 \mathrm{~g} / \mathrm{ml}$ and $1.14 \mathrm{~g} / \mathrm{ml}$ density layers. Liver lysosomes from tyloxapol-treated mice are shifted towards this interphase due to their lower density (tritosomes) while lysosomes from non-treated mice are collected at the density of $1.21 \mathrm{~g} / \mathrm{ml}(\mathrm{F} 4)$.

(D) Western blot analysis of the fractions F1 - F4 of the discontinuous sucrose gradient derived from control (- tyloxapol) and tyloxapol-treated mice. Aliquots of protein, $50 \mu \mathrm{g}$, from all fractions were separated by SDS-PAGE, blotted on PVDF membrane and successively labelled with the anti-NCU-G1 antiserum and the anti- 
LAMP-1 antibody (1D4B). F2 represents the lysosome-enriched fraction in tyloxapoltreated mice.

Figure 5 Tyloxapol-induced density shift of lysosomes in a continuous sucrose gradient The liver from a control mouse (A) and a tyloxapol-treated mouse (B) were differentially centrifuged as formerly described by de Duve et al. [29]. The "light mitochondria" fraction (L) was top loaded onto a preformed $15-30 \%$ continuous sucrose gradient and centrifuged as indicated in the Material and methods section. Eleven fractions $(1-11)$ were collected from the top and the pellet was resuspended in sucrose solution $(P)$. All fractions were analysed by Western blotting using the indicated antibodies (A, B) and for $\beta$-hexosaminidase activity (C). The open squares ( $\square$ ) indicate the sucrose gradient derived from the control mouse (- Tyloxapol); the filled circles $(0)$ the gradient derived from the tyloxapol-treated mouse. 
Biochemical Journal Immediate Publication. Published on 02 Jun 2009 as manuscript BJ20090567

\section{Figure 1}

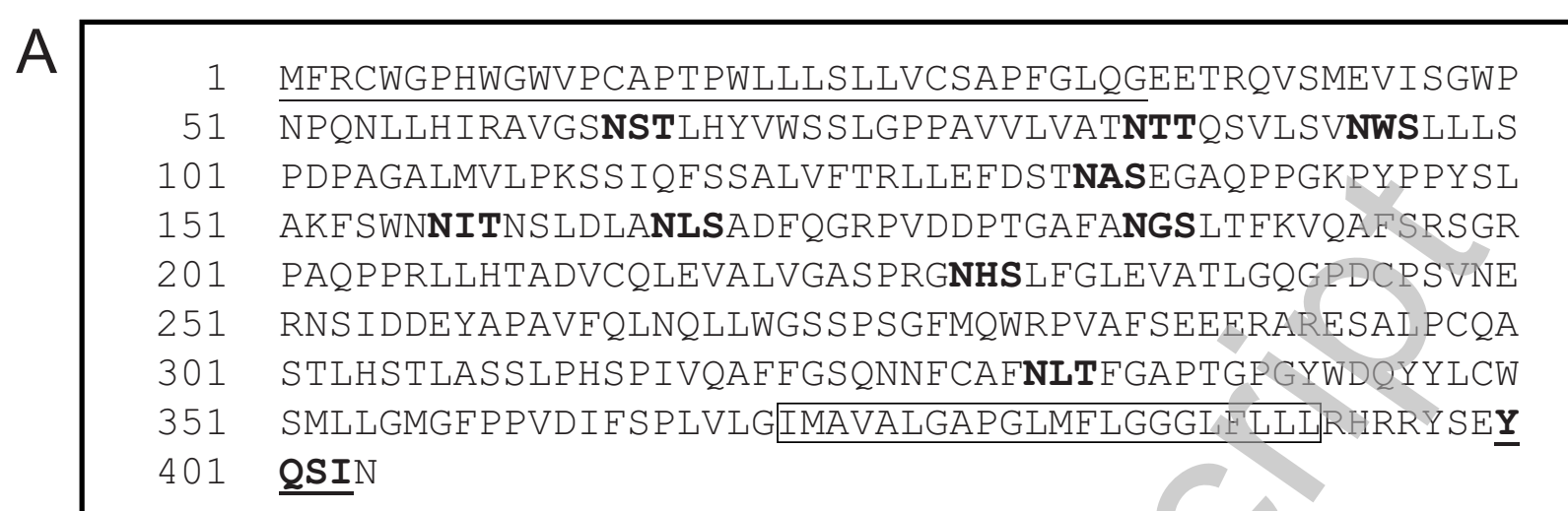

B

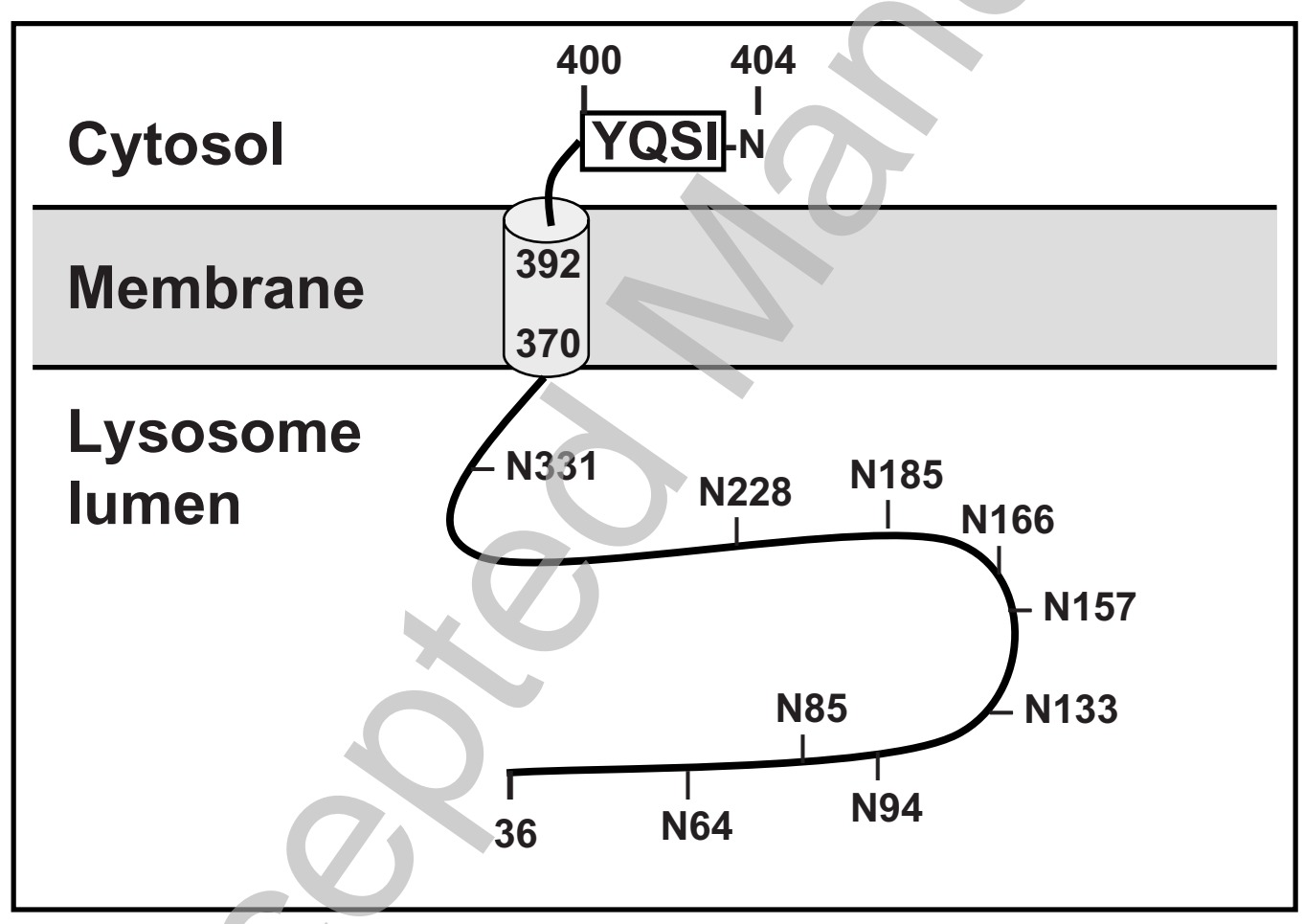

Licenced copy. Copying is not permitted, except with prior permission and as allowed by law. (C) 2009 The Authors Journal compilation (c) 2009 Portland Press Limited 
Biochemical Journal Immediate Publication. Published on 02 Jun 2009 as manuscript BJ20090567

Figure 2

A
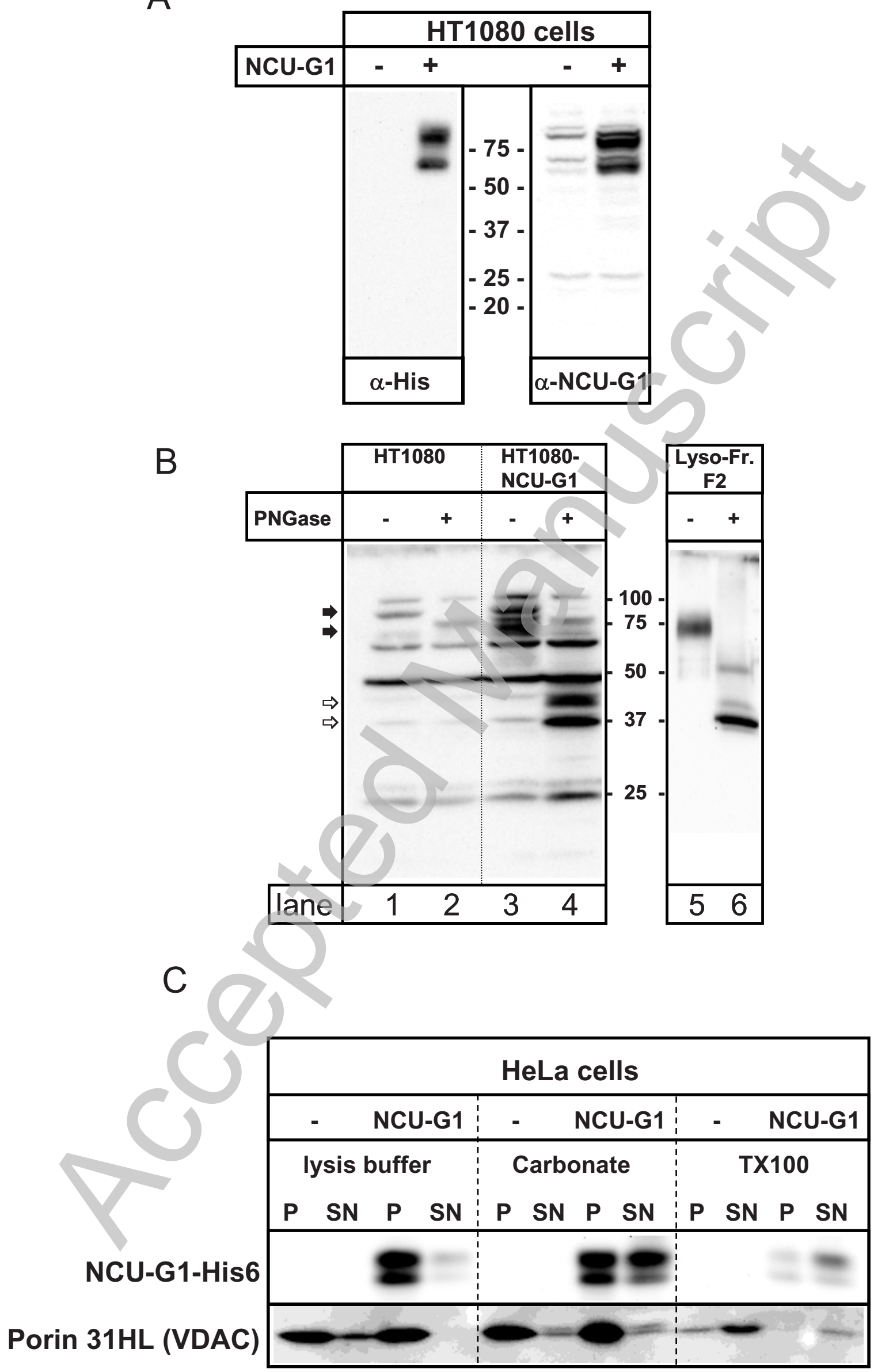
Figure 3

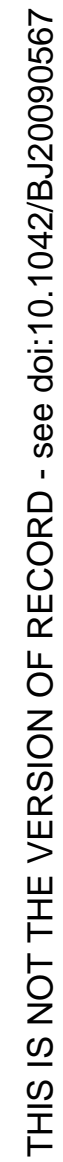

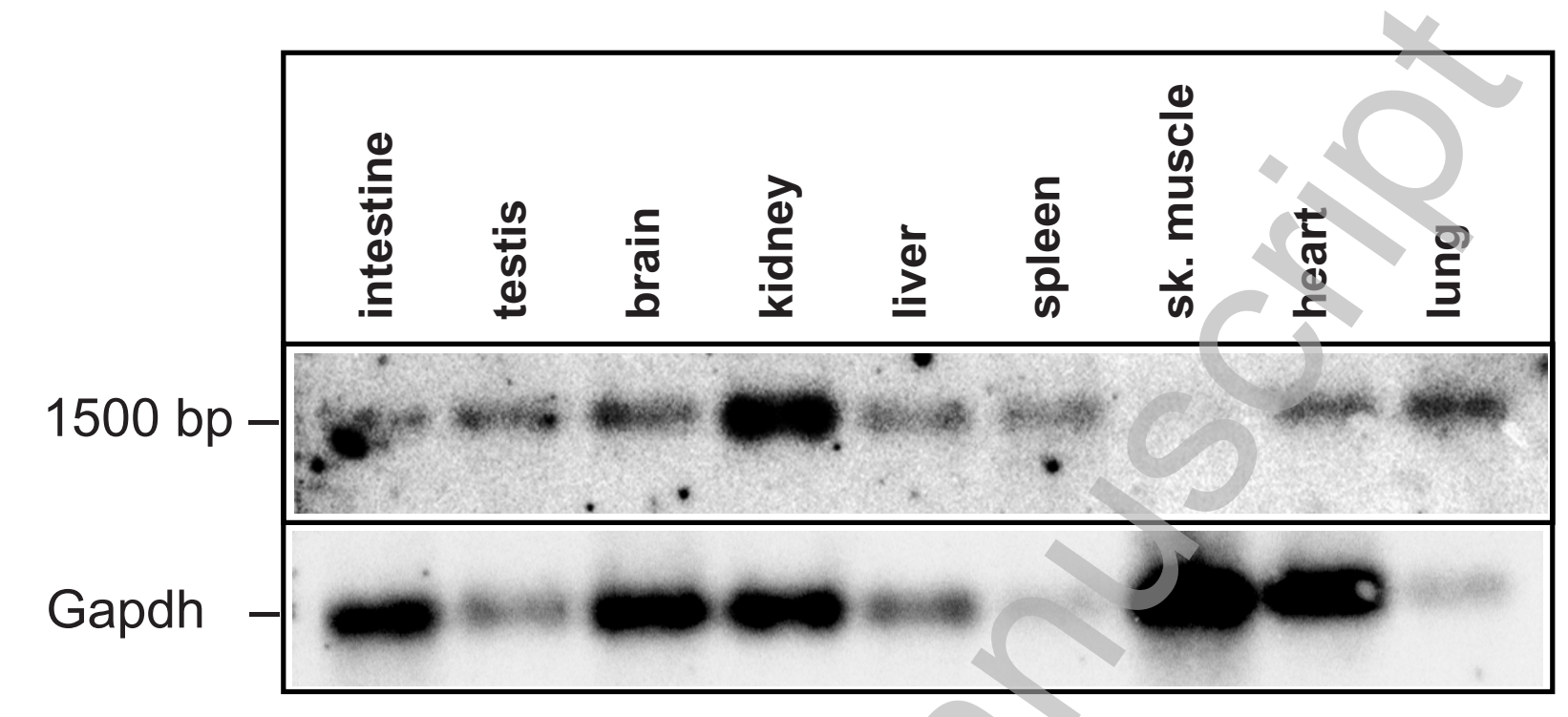


Biochemical Journal Immediate Publication. Published on 02 Jun 2009 as manuscript BJ20090567

Figure 4

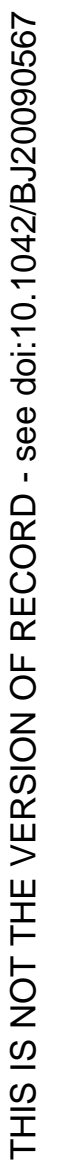
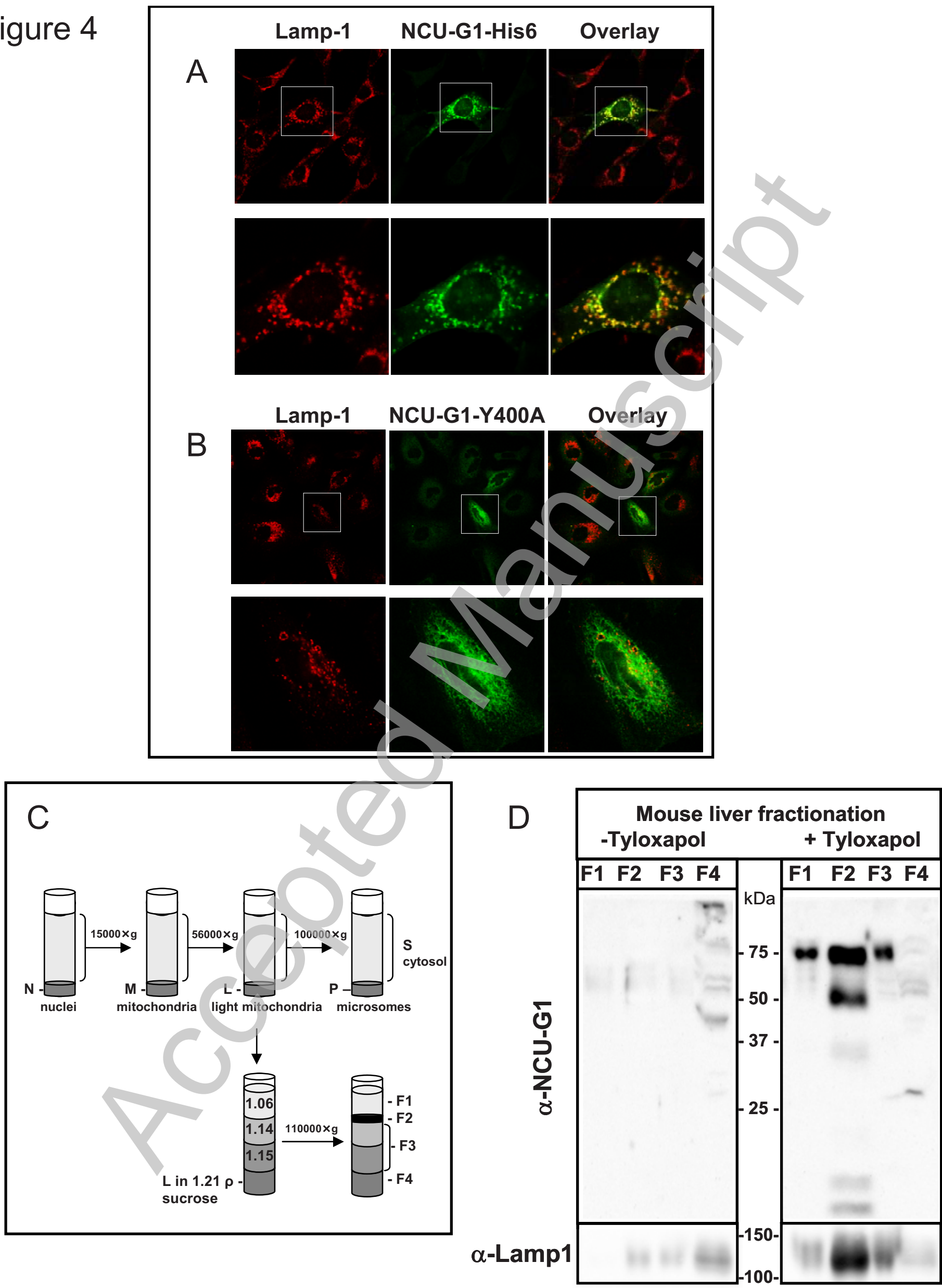

Licenced copy. Copying is not permitted, except with prior permission and as allowed by law. (C) 2009 The Authors Journal compilation (c) 2009 Portland Press Limited 
Biochemical Journal Immediate Publication. Published on 02 Jun 2009 as manuscript BJ20090567

Figure 5
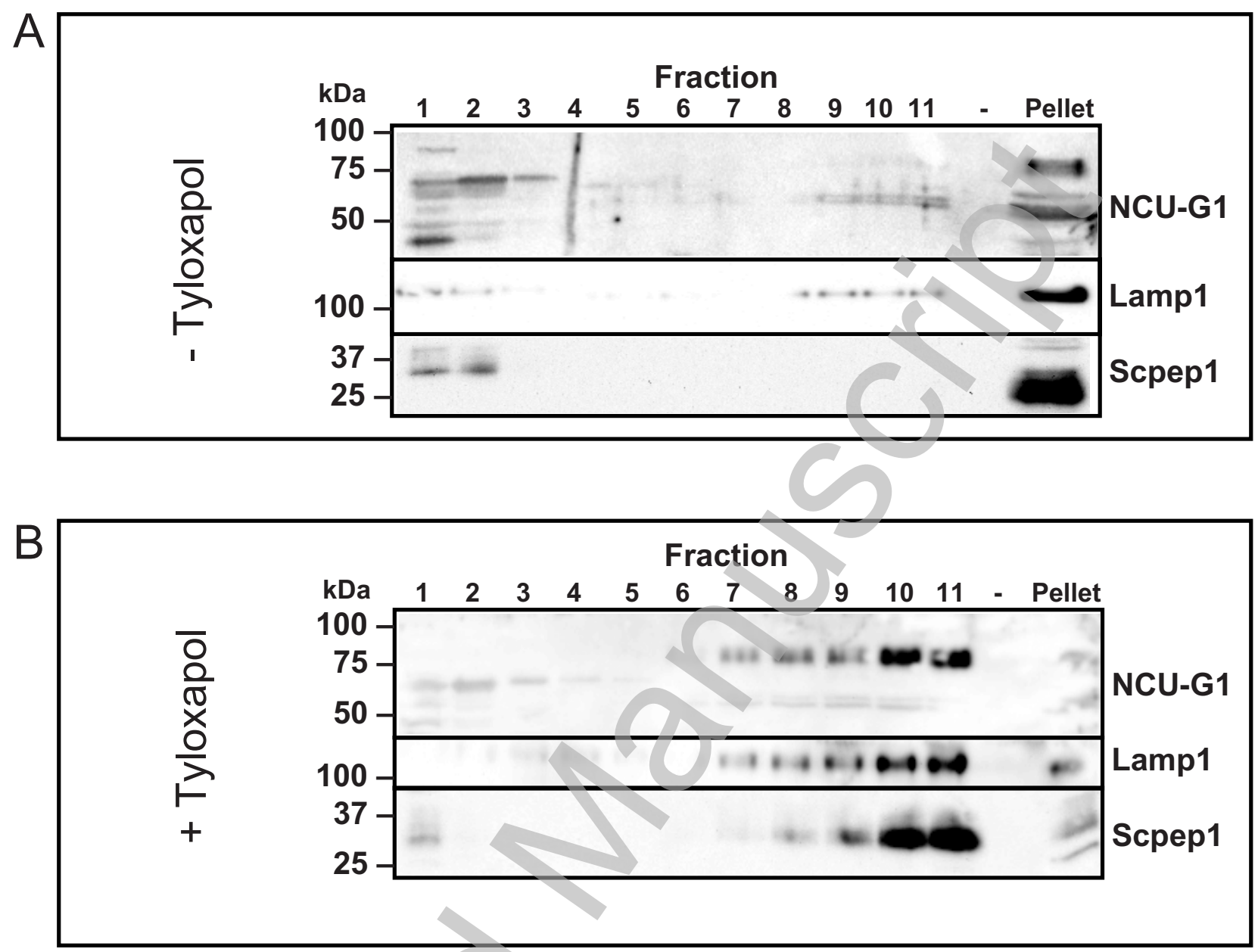

C

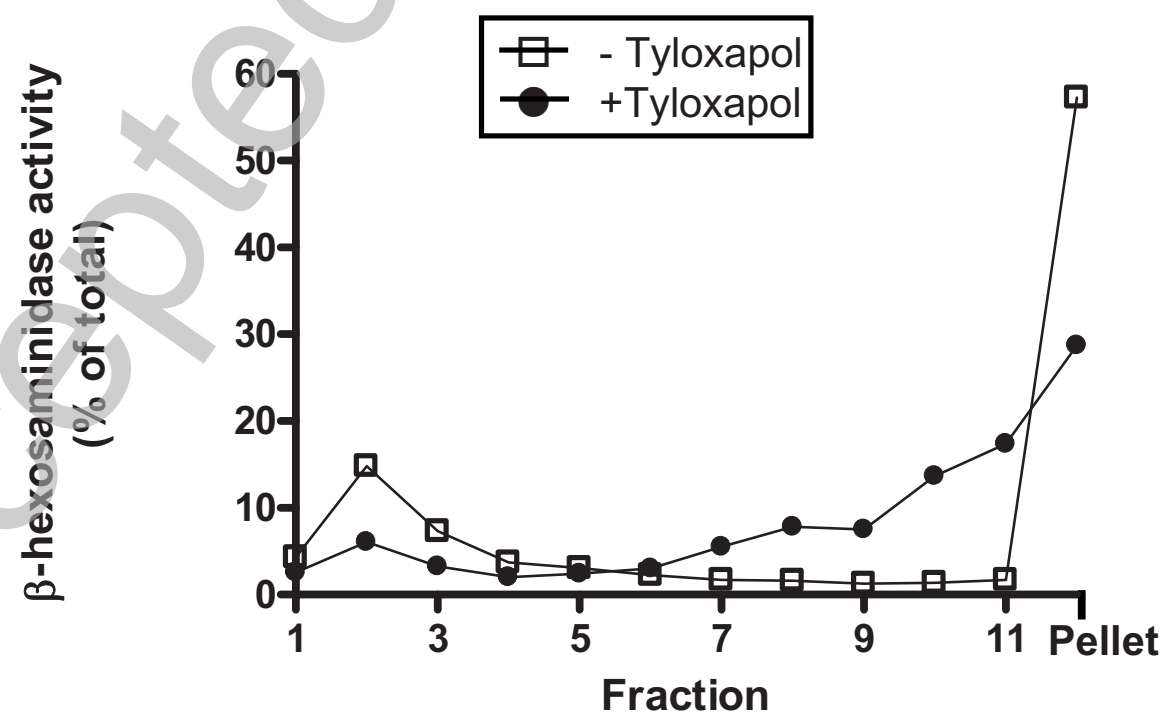

Licenced copy. Copying is not permitted, except with prior permission and as allowed by law.

(C) 2009 The Authors Journal compilation (c) 2009 Portland Press Limited 